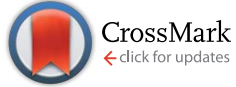

Cite this: RSC Adv., 2015, 5, 51883

\title{
Polyethyleneimine for copper absorption II: kinetics, selectivity and efficiency from seawater $\uparrow$
}

\author{
Johan B. Lindén, ${ }^{a}$ Mikael Larsson, ${ }^{* a}$ Simarpreet Kaur, ${ }^{a}$ William M. Skinner, ${ }^{a}$ \\ Stanley J. Miklavcic, ${ }^{b}$ Thomas Nann, ${ }^{a}$ Ivan M. Kempson ${ }^{a}$ and Magnus Nydén ${ }^{a}$
}

Glutaraldehyde (GA) cross-linked polyethyleneimine (PEI) coatings have previously been reported to effectively and selectively take up copper from seawater relevant concentrations in artificial seawater. We evaluate the copper uptake of such coatings from natural seawater. X-ray photoelectron spectroscopy elemental analysis revealed the coatings to be highly efficient and equally selective for copper uptake in natural seawater, reaching a maximum copper loading of $2 \mathrm{wt} \%$ in 48 hours. Similar to observations in artificial seawater we found that zinc was initially accumulated in the coatings, but was exchanged by copper over time. We investigate the spatial distribution of copper in the coatings by time-of-flight secondary ion mass spectrometry (ToF-SIMS), which revealed that copper was evenly distributed in the coating, with the exception of lower concentrations at the coating-water interface. We use synchrotron X-ray absorption studies and Fourier transform infrared (FTIR) spectroscopy to show that the copper-ligand interaction was mediated by Schiff's bases (imines).

Received 1st May 2015

Accepted 3rd June 2015

DOI: $10.1039 / \mathrm{c} 5 \mathrm{ra0} 8029 \mathrm{k}$

www.rsc.org/advances

electrochemical stimulus for switching the function of the

\section{Introduction}

Materials with the ability to bind copper from seawater could enable remediation of copper-contaminated marine environments as well as the use of the copper for advanced marine applications. Anti-biofouling coatings on vessels are possibly the largest contaminant source of copper to marinas and copper-based anti-biofouling coatings could end up sharing similar regulations to those containing tributyltin (TBT). ${ }^{\mathbf{1 - 4}}$ The academic and industry communities working on antibiofouling coatings have so far been unable to respond to the challenge of creating new environmentally friendly and biocidefree alternatives with performance comparable to currently used coatings that release copper as the main biocidal agent.

We propose here an anti-biofouling mechanism based on cycles of accumulation and release of copper naturally abundant in seawater to create a biocidal flux of copper across an interface, i.e., a coating that uses the well-documented biocidal effect of copper without any net release of copper into the sea. The mechanism relies on copper-selective polymers for uptake and electrically conducting and active polymers for triggered release. The working principle of the antibiofouling concept comprises four stages: (1) uptake of copper into the coating, (2)

\footnotetext{
${ }^{a}$ Ian Wark Research Institute, University of South Australia, Mawson Lakes, SA, 5095, Australia. E-mail: larsson.mikael@gmail.com; Fax: +61-8-830-23493; Tel: +61-8-83023493

${ }^{b}$ Phenomics and Bioinformatics Research Centre, University of South Australia, Mawson Lakes, SA, 5095, Australia

$\dagger$ Electronic supplementary information (ESI) available: XANES study of copper speciation in interaction with PEI, Fig. S1. See DOI: 10.1039/c5ra08029k
} coating into a copper-release state, (3) antibiofouling action of the released copper and (4) electrochemical stimulus for switching back to copper-uptake mode. This would enable a never-ending cycle because of the unlimited access to copper from seawater.

In this work we focused on copper-uptake from seawater, stage (1). For the concept to work, a polymeric material with extreme affinity and selectivity for copper is needed to overcome the effects of extremely low copper concentrations and competing ions in natural seawater.

Materials with extreme copper-uptake efficiency and selectivity also have potential for mining the oceans and pollution remediation. Chouyyok et al. ${ }^{5}$ showed that chelating diamines could be successfully used for the purpose of extracting copper from polluted natural waters. With respect to mining the oceans we note that the focus has been on polymer-based materials, critically reviewed by Schwochau. ${ }^{6}$ The main problem with this application is that the process is too energy demanding. ${ }^{7}$

Polyethyleneimine (PEI)-based materials have been intensively investigated for metal binding: ${ }^{8-10}$ Removal of many metal ions from wastewaters including $\mathrm{Cu}^{2+}, \mathrm{Ni}^{2+}, \mathrm{Fe}^{2+}, \mathrm{Co}^{2+}, \mathrm{Zn}^{2+}$, $\mathrm{Cd}^{2+}, \mathrm{Pb}^{2+}, \mathrm{Cr}^{3+}$ and $\mathrm{Hg}^{2+}$ has been demonstrated ${ }^{8-13}$ and they seem to have strong preference for copper, ${ }^{\mathbf{1 0 - 1 2 , 1 4}}$ although there is a deviating report. ${ }^{8}$ Due to its copper selectivity and efficiency, PEI has been used as a spectroscopic detection agent of low parts per billion (ppb) concentrations. ${ }^{15-17} \mathrm{PEI}$ is often attached to carrier particles such as silica, ${ }^{11,12,14,18}$ porous magnetic powder, ${ }^{10}$ biomass, ${ }^{19,20}$ commercial acrylic fibre, ${ }^{21}$ porous cellulose material, ${ }^{9}$ agarose beads ${ }^{22,23}$ poly(methyl methacrylate) 
microspheres ${ }^{8}$ and polystyrene-based macroporous cation exchange resin. ${ }^{24}$

Branched PEI binds metal ions stronger than linear versions $^{25}$ and typically consists of primary, secondary and tertiary amines in $1: 1: 0.7$ ratios $^{26}$ with branching sites every 3-3.5 nitrogen atoms. ${ }^{27}$ PEI has the advantages of good hydrophilicity, fast rate of adsorption and high adsorption capacity. ${ }^{28,29}$ Moreover PEI does not chelate alkali or alkaline earth metals at any $\mathrm{pH}$, which is advantageous in water with high salt content as in the case of seawater. ${ }^{18,30}$

In a recent communication ${ }^{31}$ we reported on the potential of glutaraldehyde (GA) cross-linked PEI for selective extraction of copper. Nano-thin coatings were shown to accumulate up to 5-13 wt\% copper from artificial seawater containing 2-200 ppb copper, e.g., concentrations relevant to polluted harbours and marinas. The work further revealed a time-dependant competitive binding and replacement mechanism between copper and zinc.

In a recent publication we investigated possible scenarios for the replacement mechanism by mathematical modelling. ${ }^{32} \mathrm{We}$ showed that difference in uptake kinetics and equilibrium content of copper and zinc can be explained by a combination of (a) differing ion diffusive rates and (b) an ion exchange process that is superimposed on the independent binding processes. The difference in uptake kinetics could be due to differences in hydrated size of the metal complexes and the ion exchange process likely involves conformational changes in the polymer structure in response to the binding of one of the species. $^{32}$

In this paper we evaluate the performance of the GA crosslinked PEI coatings in natural seawater and further investigate the competitive binding between copper and zinc. Furthermore, we characterise the copper distribution in the coatings and the copper-ligand chemistry. We determine the uptake of copper and zinc by X-ray photoelectron spectroscopy (XPS) and evaluate the distribution of copper in the coatings with time-of-flight secondary ion mass spectrometry (ToFSIMS). Finally, we use FTIR and synchrotron X-ray absorption spectroscopy (XAS) to study the chemistry of the copper-PEI interaction.

\section{Experimental}

\section{Materials}

All chemicals were purchased as analytical or reagent grade and used as received without further purification. Branched polyethyleneimine ( $50 \mathrm{wt} \%$ in $\mathrm{H}_{2} \mathrm{O}, M_{\mathrm{n}} \sim 60000$ and $\mathrm{MW} \sim 750000$ ) and glutaraldehyde ( $25 \mathrm{wt} \%$ in $\mathrm{H}_{2} \mathrm{O}$ ) were purchased from Sigma-Aldrich and stored under $\mathrm{N}_{2} \cdot \mathrm{ZnCl}_{2}$ was purchased from Scharlau, Scharlab S.L. Copper(II) sulphate pentahydrate $\left(\mathrm{CuSO}_{4} \cdot 5 \mathrm{H}_{2} \mathrm{O}\right)$ and sodium hydroxide $(\mathrm{NaOH})$ pellets were purchased from Chem-Supply Pty Ltd. Sea salts $\left(40 \mathrm{~g} \mathrm{~L}^{-1}\right.$, Sigma-Aldrich) was used to prepare artificial seawater. Ultrapure water with a resistivity of $18.2 \mathrm{M} \Omega \mathrm{cm}$ was obtained using a Milli-Q ${ }^{\circledR}$ Advantage $A 10 \circledR$ water purification system. Seawater was collected at Outer Harbour, Adelaide, South Australia, Australia (coordinates $34^{\circ} 46^{\prime} 49.0^{\prime \prime} \mathrm{S} 138^{\circ} 28^{\prime} 49.4^{\prime \prime} \mathrm{E}$ ).
For XAS, copper(II)oxide (CuO), copper(I)oxide $\left(\mathrm{Cu}_{2} \mathrm{O}\right)$, EDTA tetrapotassium salt, ammonia solution, copper(II)nitrate $\left(\mathrm{Cu}\left(\mathrm{NO}_{3}\right)_{2} \cdot 3 \mathrm{H}_{2} \mathrm{O}\right)$, copper(I)chloride $(\mathrm{CuCl})$, copper(II)chloride $\left(\mathrm{CuCl}_{2}\right)$ and ethylenediamine were all purchased from SigmaAldrich. Ligands were mixed with copper(II)sulphate pentahydrate $\left(\mathrm{CuSO}_{4} \cdot 5 \mathrm{H}_{2} \mathrm{O}\right)$ in Milli-Q water, while the copper salts were mixed with Milli-Q water for liquid standards or microcrystalline cellulose (powder, $20 \mu \mathrm{m}$, Sigma-Aldrich) for solid standards.

\section{Ellipsometry}

Dry layer thicknesses were determined using a Variable Angle Spectroscopic Ellipsometer (VASE®) and WVASE32® software (J.A. Woollam Co., Inc.) with the thickness of the coatings being modelled as a Cauchy layer on a sublayer with the optical constants of the used silicon wafers.

\section{X-ray photoelectron spectroscopy (XPS)}

XPS measurements were undertaken using monochromatized $\mathrm{Al} \mathrm{K} \alpha$ X-rays $(1486.7 \mathrm{eV})$ at a power of $225 \mathrm{~W}$ on a Kratos AxisUltra spectrometer (160 eV analyzer pass energy for survey scans, $20 \mathrm{eV}$ for high-resolution scans). The analysis spot size was $\sim 300 \times 700 \mu \mathrm{m}$. Core electron binding energies are given relative to an adventitious hydrocarbon $\mathrm{C}$ 1s binding energy of $284.8 \mathrm{eV}$. Two spots per sample were analyzed and averaged to determine elemental composition within a sample. All XPS spectra were processed with CasaXPS (ver. 2.3.16 PR 1.6) data processing software using a Shirley background correction. Atomic ratios of metal to nitrogen provided an evaluation of the coordination of the metals to nitrogen in the coating.

\section{Attenuated total reflectance-Fourier transform infrared spectroscopy (ATR-FTIR)}

Attenuated total reflectance Fourier transform infrared (ATRFTIR) spectra were obtained using a Bruker Hyperion 1000 IR microscope operating with a Bruker Vertex 80 IR spectrometer. The IR microscope was equipped with a liquid nitrogen cooled MCT detector. Samples were prepared on $\sim 4 \mathrm{~cm}^{2}$ microscope slides (coating type: Ti/Au, thickness: $40 \mathrm{~nm} / 100 \mathrm{~nm}$, DRLI). ATR spectra were collected over 64 scans, with a resolution of 4 $\mathrm{cm}^{-1}$, using a Ge ATR crystal. Spectra of the PEI coatings were recorded using OPUS version 7.0 software in the range of 650$4000 \mathrm{~cm}^{-1}$ and analysed using OMNIC FTIR spectroscopy data analysis software in the range of $1000-4000 \mathrm{~cm}^{-1}$. All IR spectra were processed by auto-correction of baseline and smoothing before subtraction of a control spectrum of a bare gold coated microscope slide to remove any signals from the substrate.

\section{Time-of-flight secondary ion mass spectrometry (ToF-SIMS)}

A Physical Electronics Inc. PHI TRIFT V nanoTOF (Physical Electronics, Inc., Chanhassen, MN) ToF-SIMS was used for conducting depth profiles through coatings. Sputtering was performed over a $500 \times 500$ micron area with a $20 \mathrm{kV} \mathrm{C}_{60}$ ion source for 5 second intervals and a source current of 7 nA. Between sputtering, spectra were acquired for 2 minutes with a 
$30 \mathrm{kV} \mathrm{Au}^{+}$liquid metal ion gun with a total primary ion dose less than $10^{10}$ ions $\mathrm{cm}^{-2}$ to remain within static limits.

\section{X-ray absorption near edge spectroscopy (XANES)}

XANES was conducted at the XAS beamline at the Australian Synchrotron using a 1.9T Wiggler insertion device and a $\mathrm{Si}(111)$ monochromator. Nominal specifications gave an energy resolution of $1.5 \times 10^{-4}$, beam size of $250 \times 250$ microns and a flux of $10^{10}$ to $10^{12} \mathrm{ph} \mathrm{s}^{-1}$. Absorption of the incident X-ray beam was monitored by fluorescence with a 100 element germanium detector perpendicular to the incident beam. Except for powder standards, samples were analysed hydrated. Standards in solution were encapsulated in a Perspex mount with kapton foil windows and plunge frozen in liquid nitrogen. PEI coatings, after copper absorption, were quickly rinsed with Milli-Q water and immediately plunge frozen in liquid nitrogen. Cryogenic temperatures were maintained between 5 and $10 \mathrm{~K}$ for the duration of analysis. XANES was performed over the $\mathrm{Cu}-\mathrm{K}$ edge $(8979 \mathrm{eV})$ with the pre-edge region acquired in $10 \mathrm{eV}$ steps before using $0.25 \mathrm{eV}$ steps from 8975 to $9012.5 \mathrm{eV}$ followed by 0.06 steps in $\mathrm{K}$ out to $6 \mathrm{~K}$. Data across detector elements were averaged using the 'Average' software package and further postprocessed with Athena. ${ }^{33,34}$

\section{Preparation of cross-linked PEI coatings}

Cross-linked PEI coatings were prepared according to a previously reported method. ${ }^{31}$ Briefly, the coatings were prepared in three steps on $\sim 1 \mathrm{~cm}^{2}$ silicon wafer substrates. First a thin layer of PEI was spin coated from a solution in ethanol, thereafter cross-linking was conducted by immersion in GA. The samples were then immersed in a solution of PEI in Milli-Q water before washing and gentle drying using $\mathrm{N}_{2}$ (Scheme 1). The GA crosslinking technique was adapted from Tong et $a l .^{35}$ The average dry layer thicknesses of the coatings were determined in previous work ${ }^{31}$ to be $8 \mathrm{~nm}$ (S.D. $1.1 \mathrm{~nm}, n=32$ ) by ellipsometry.

\section{Preparation of solutions}

Spiked seawater was prepared by adding $50 \mathrm{~L}$ of collected seawater without further purification into a $100 \mathrm{~L}$ general plastic storage container. $1.52 \mathrm{~mL}$ of $1 \mathrm{mM}$ copper sulphate $\left(\mathrm{CuSO}_{4}\right)$ solution was added to spike the seawater with $\sim 2 \mathrm{ppb}$ copper. Non-spiked seawater was prepared by adding $7 \mathrm{~L}$ of collected seawater without further purification into a general plastic bucket.

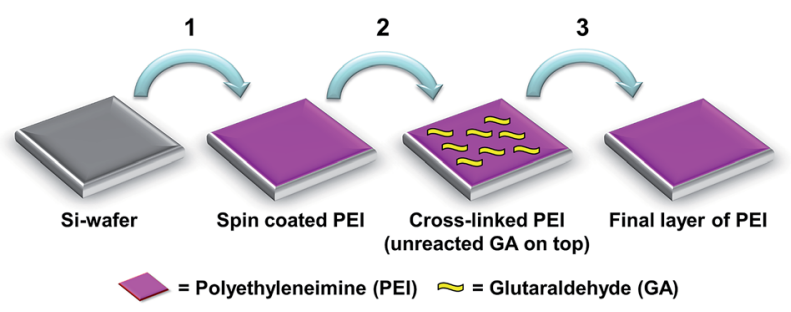

Scheme 1 Preparation of cross-linked PEI coatings. Reproduced from ref. 31.
Artificial seawater was prepared by mixing $40 \mathrm{~g}$ of sea salts per litre of Milli-Q water. $1 \mathrm{mM} \mathrm{CuSO}{ }_{4}$ and $\mathrm{ZnCl}_{2}$ solutions in Milli-Q water were prepared and added to the artificial seawater solution to achieve equimolar concentration of $3.15 \mu \mathrm{M}$, which corresponds to $200 \mathrm{ppb}$ for $\mathrm{Cu}^{2+}$ and $206 \mathrm{ppb}$ for $\mathrm{Zn}^{2+}$.

The $\mathrm{pH}$ of solutions was determined to $\sim 8.1$ using an ION 700 meter equipped with a $\mathrm{pH}$ electrode (Eutech instruments, Singapore).

\section{Copper absorption from artificial seawater and seawater}

The volumes used for absorption studies contained more than ten times excess of copper ions relative to the estimated maximum copper uptake by the coatings, estimated as follows: thickness $=15 \mathrm{~nm}$, area $=1 \mathrm{~cm}^{2}$, maximum uptake ratio of copper-to-nitrogen ${ }^{16,36}=0.25$, coating composition $=100 \%$ PEI.

For absorption from seawater all samples were immersed in

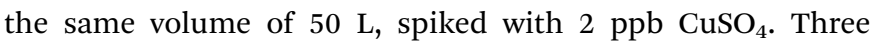
additional samples were immersed separately in $7 \mathrm{~L}$ of seawater without added copper for comparison at the longest time point.

For absorption from artificial seawater with added zinc and copper, samples were immersed individually in glass bottles. Samples were removed at pre-determined time points, rinsed with Milli-Q water and dried with $\mathrm{N}_{2}$ before further characterisation. Samples were prepared in triplicate for each time point.

\section{Results and discussion}

\section{Copper absorption from seawater}

Nano-thin ( $8 \mathrm{~nm}$, S.D. $1 \mathrm{~nm}, n=32$ ) coatings of GA cross-linked PEI have previously been shown to effectively and selectively absorb copper from artificial seawater containing copper in concentrations relevant to contaminated seawater (2-200 $\mathrm{ppb}) .{ }^{31}$ Here it was demonstrated that such coatings efficiently accumulated copper from seawater, see Fig. 1. Given the high variability of copper concentration in the sea, 2 ppb copper was added (spiked sample) to ensure a minimum concentration. The uptake was equally effective also for the samples immersed in the non-spiked seawater. Equilibrium absorption was reached after approximately 48 hours, at which time the copperto-nitrogen ratio was $\sim 0.02$, corresponding to $2 \mathrm{wt} \%$ copper in the coating (estimated using calculations described previously ${ }^{31}$ ). Compared to the uptake from artificial seawater containing $2 \mathrm{ppb}$ copper, the rate of copper-uptake in natural seawater was slower and the copper-to-nitrogen ratio was 50\% lower at equilibrium. This could be due to the presence of competing ligands in the natural seawater. ${ }^{37}$ Seawater also contains significant amounts of dissolved organic carbon $(\mathrm{DOC})^{38}$ and it is well-known that polysaccharides and proteins rapidly accumulate on surfaces immersed in seawater, forming a conditioning film. ${ }^{39-41}$ Thus, it is reasonable to assume that deposition will occur on the PEI coatings over time and possibly influence the copper uptake.

In an attempt to investigate the formation of a conditioning film, angle-resolved XPS analysis was conducted on coatings immersed in seawater for 3 and 192 hours. While the carbon atomic percentage did not increase significantly between 3 and 


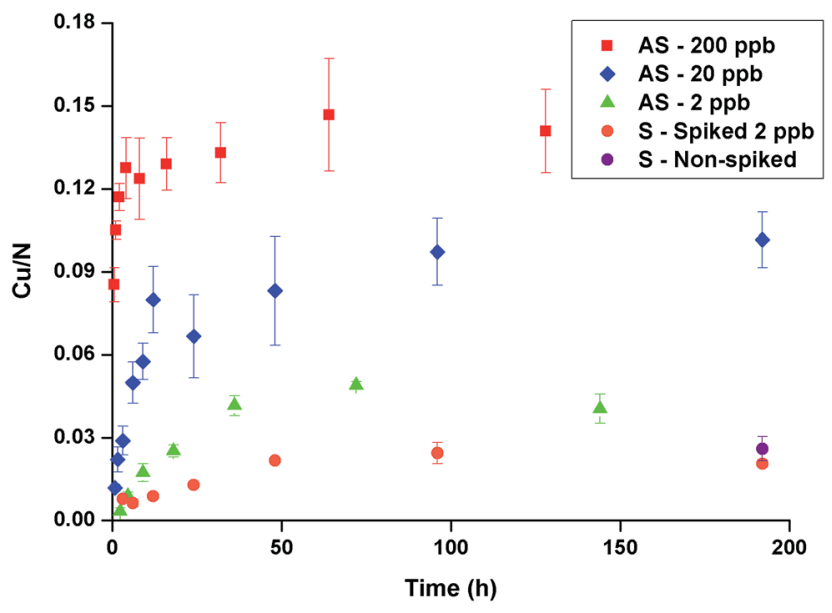

Fig. 1 Copper-to-nitrogen ratio vs. time in artificial seawater (AS) spiked with 200-2 $\mathrm{ppb} \mathrm{CuSO}_{4}$ or seawater (S) spiked with $2 \mathrm{ppb}$ $\mathrm{CuSO}_{4}$. In addition samples in non-spiked seawater were analysed at $192 \mathrm{~h}$ ("Non-spiked"). The data for artificial seawater was adapted from Lindén et al. ${ }^{31}$ Error bars indicate standard deviation of measurements $(n=3)$.

192 hours of immersion (Fig. 2), the carbon-to-nitrogen ratio did, especially amplified in the grazing exit angle measurement. Moreover, the carbon-to-silicon ratio also increased while the nitrogen-to-silicon was constant, which is significant in that we know from previous work ${ }^{31}$ that the PEI coatings contain sparse distributions of imperfections/holes which result in the Si wafer substrates being "visible" to XPS. This implies that conditioning films were formed over time on the PEI coatings while immersed in seawater.

\section{Copper selectivity}

We have previously shown that GA cross-linked PEI selectively accumulated copper from artificial seawater with 12 seawaterrelevant metals added. Although zinc absorbed faster it was replaced by copper at longer times. ${ }^{31}$ As shown in Fig. 3A, the behaviour in seawater was similar to artificial seawater; zinc

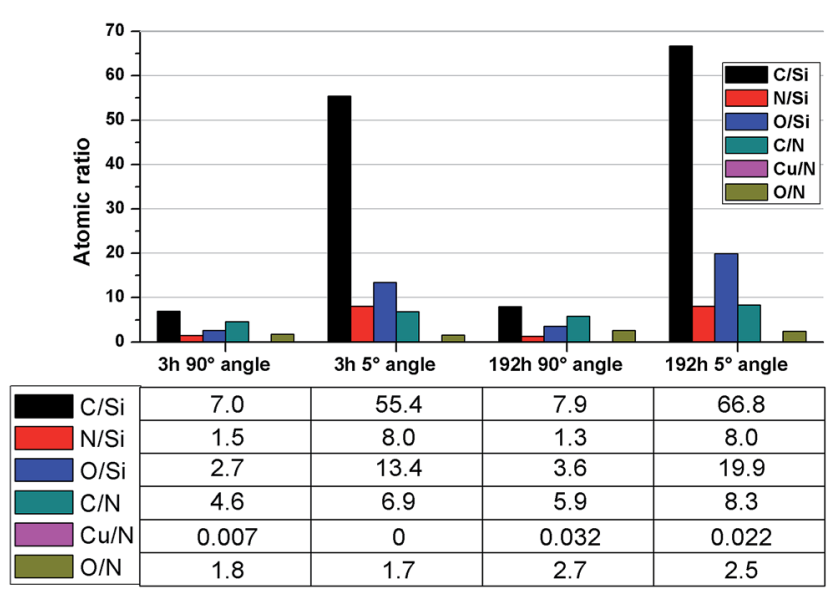

Fig. 2 XPS results of atomic ratios after 3 and 192 hours seawater exposure, acquired at 90 and 5 degrees angle. initially competed for binding sites but was replaced by copper over time.

To study the competitive binding processes in more detail, samples were immersed in artificial seawater with only copper and zinc added to the same molar concentration $(3.15 \mu \mathrm{M}=200$ ppb $\mathrm{Cu}^{2+}, 206 \mathrm{ppb} \mathrm{Zn}^{2+}$ ) and the metal uptake was evaluated over time, Fig. 3B. Again zinc was exchanged by copper. Thus, the phenomenon was inherent to copper and zinc and did not depend on other metals.

To further study the mechanism behind the competitive binding processes mathematical modelling was used. Fig. 4 shows results of the competitive ion exchange process model described in detail as Scenario I in Miklavcic et al. ${ }^{32}$ For these results, the diffusion constants of zinc and copper ions were approximately the same, with zinc having a slight kinetic advantage; both ions were assumed to bind with free PEI sites with identical strength (identical binding rate constants). However, as copper ions entrained into the PEI matrix (Fig. 4A) via a forced diffusive process they progressively bind with both
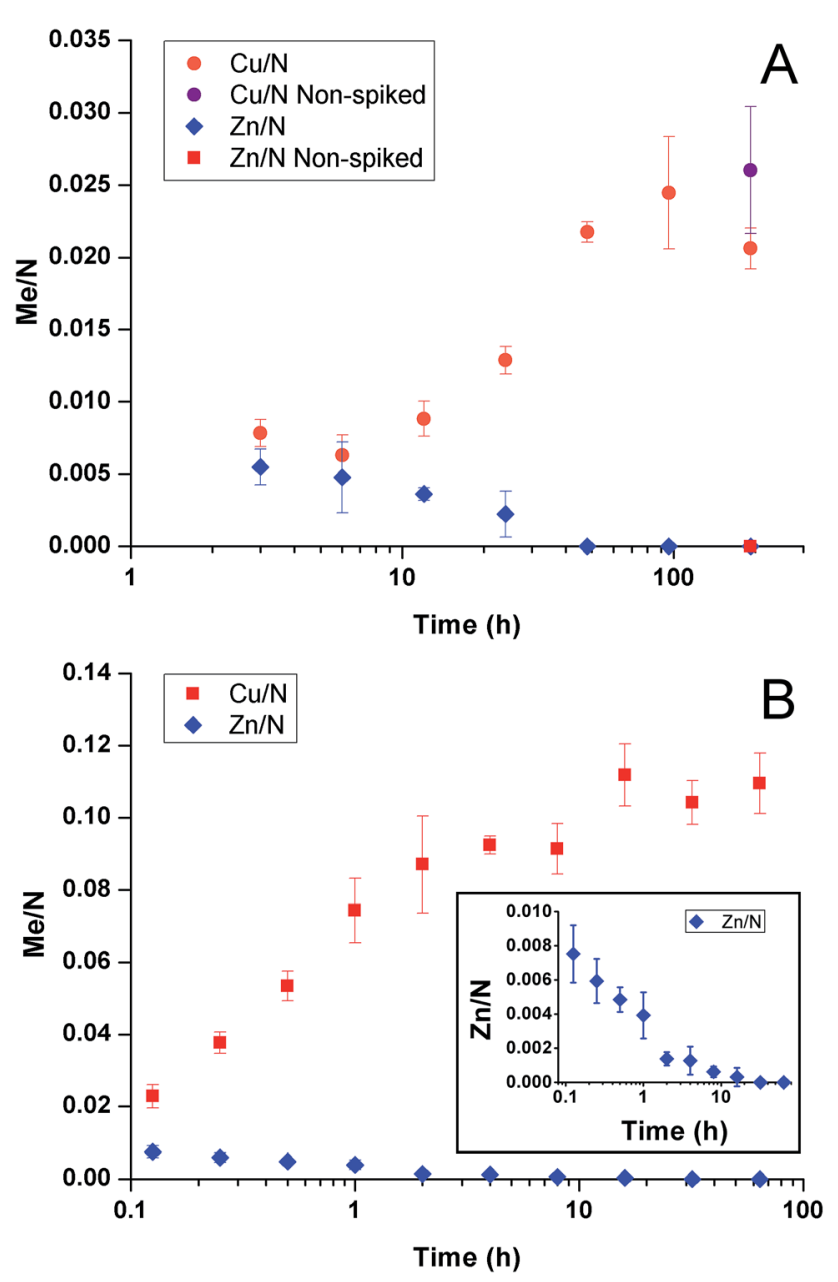

Fig. 3 Metal-to-nitrogen ratio as a function of time. (A) After immersion in seawater spiked with $2 \mathrm{ppb} \mathrm{CuSO}_{4}$ and after 192 hours in non-spiked seawater ("Non-spiked"). (B) After immersion in artificial seawater $\left(\left[\mathrm{Cu}^{2+}\right]=3.15 \mu \mathrm{M}=200 \mathrm{ppb},\left[\mathrm{Zn}^{2+}\right]=3.15 \mu \mathrm{M}=206 \mathrm{ppb}\right)$. Inset showing the zinc-to-nitrogen ratio over time in more detail. Error bars indicate standard deviation of measurements $(n=3)$. 
free PEI absorption sites as well as with sites already occupied by zinc ions, preferentially replacing the latter. Thus, although zinc diffused into the matrix slightly ahead of copper, forming ZnPEI complexes first, these complexes were destabilised by copper which formed new CuPEI complexes instead. Thus, the conditions assumed led to a transient front of ZnPEI complexes, which moved further and further into the matrix (indicated by the arrow in Fig. 4B). In this figure, the bound ion densities are given as functions of independent variables: $y=\kappa x$ and $s=$ $t D_{\mathrm{m}} \kappa^{2}$, being dimensionless distance and time, respectively. The spatial variable $x$ represents position in the polymer matrix (zero at the substrate wall and one at the outer extreme of the PEI layer), $\kappa$ is the Debye constant for the electrolyte and $D_{\mathrm{m}}$ is the maximum diffusion constant of mobile ions. The densities themselves were normalised with respect to the maximum bulk ion density (here being the $\mathrm{Cl}$ ion concentration). Full details of the binding and exchange processes are given in Miklavcic et al. $^{32}$

\section{Spatial distribution of copper}

ToF-SIMS is an extremely surface sensitive analytical tool and will probe the surface $2-3 \mathrm{~nm}$ during analysis in each cycle. ${ }^{42}$ To characterise the spatial distribution of copper in the nano-thin coatings after immersion in seawater, ToF-SIMS was used to generate depth profiles through the coating by interleaving analysis and sputtering cycles. The experiment allowed a component-resolved spatial profile going into the coating and to the silicon substrate. The resulting mass spectra are inherently intricate and the fragmentation patterns can reveal compositional and subtle structural information in complex systems. ${ }^{43,44}$ It has further been demonstrated to provide information on ligand formation between organic and inorganic materials. ${ }^{45}$
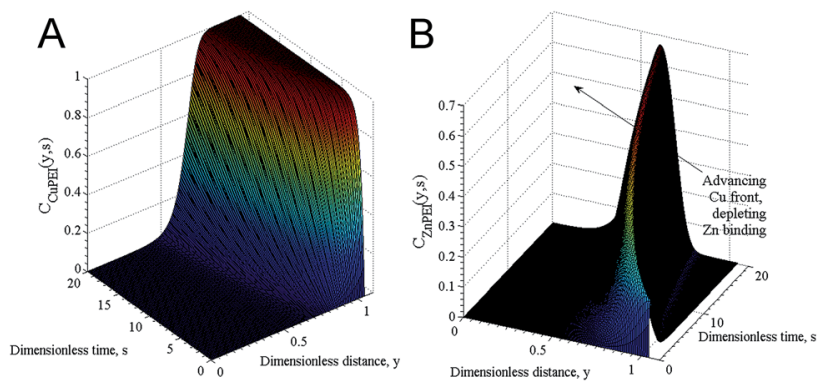

Fig. 4 Normalised bound ion densities as a function of dimensionless time and position. (A) Shows the time development of the density of the CUPEI complex, while (B) shows the density corresponding to the $\mathrm{ZnPEl}$ complex. Note that (B) has been rotated clockwise 90 degrees to highlight the depletion zone behind an initial front of $\mathrm{ZnPEI}$ complexes that results from the replacement of zinc with copper ions. For these results, we assigned diffusion constants of $D_{\mathrm{Cu}}$ $=2.263 \times 10^{-6} \mathrm{~cm}^{2} \mathrm{~s}^{-1}$ and $D_{\mathrm{Zn}}=2.274 \times 10^{-6} \mathrm{~cm}^{2} \mathrm{~s}^{-1}$, ion concentrations $\mathrm{C}_{\mathrm{CuCl}_{2}}=\mathrm{C}_{\mathrm{ZnCl}_{2}}=3 \mu \mathrm{M}$ with an inert background univalent electrolyte concentration of $1 \mathrm{mM}$. Using the nomenclature of Miklavcic et al., 32 the equilibrium binding strengths assigned were $k_{1+} / k_{1-}=k_{2+} / k_{2_{-}}=1.25 \times 10^{5}$, with the exchange reaction strength of $k_{3+} / k_{3-}=1.0 \times 10^{12}$.
Here, the results from ToF-SIMS depth profiles through PEI coatings exposed to seawater spiked with $2 \mathrm{ppb} \mathrm{CuSO}_{4}$ are revealed and discussed. We have observed a $\mathrm{CuNCH}^{+}$fragment to be indicative of the copper distribution and how it was primarily associated in the coating. The absolute numbers of ions detected, normalised to the total ion yield, are shown in Fig. $5 \mathrm{~A} . \mathrm{Si}^{+}$represents the substrate. The 3 hour time point revealed very little penetration of copper into the coating. After 24 and 192 hours immersion, the copper distribution appeared comparable, with the copper residing in a band below the surface, suggesting a non-copper binding region at the very top, in line with XPS-results and the hypothesis that a conditioning film formed at the coating surface. The composition of the copper-based fragment is suggestive of the copper binding with the polymer via the amine groups. Furthermore, the peak intensity for $\mathrm{CuNCH}^{+}$, can be interpreted in a semi-quantitative way. ToF-SIMS is highly matrix sensitive, however, here the matrix should be identical between each sample and the change in peak intensity should be due to a genuine variation in copper concentration. We estimate that roughly $1 \mathrm{~nm}$ of material has been removed in each sputter cycle. At the atomic level this is quite variable however and features in structure as a function of depth lose distinction, as seen in the broad distributions in the depth profile plot (Fig. 5A). A 3D reconstruction of the analysis conducted for the 24 hour time point is given in Fig. 5B. This figure aids in visualisation of the copper distribution in the coating.

\section{ATR-FTIR analysis of PEI coatings}

To provide information on the chemistry of the GA cross-linked PEI and copper binding, ATR-FTIR analysis was conducted before and after cross-linking and after copper uptake from artificial seawater containing $200 \mathrm{ppb}$ copper added in the form of $\mathrm{CuSO}_{4}$, with spectra presented in Fig. 6. C-H stretches were observed for spin coated PEI at $2836 \mathrm{~cm}^{-1}$ and $2947 \mathrm{~cm}^{-1} \cdot{ }^{46}$ After cross-linking, the $\left(\mathrm{CH}_{2}\right)_{n}$ band at $2947 \mathrm{~cm}^{-1}$ appeared more distinct, indicating the presence of glutaraldehyde. ${ }^{18} \mathrm{An}$ imine band $\left(\mathrm{C}=\mathrm{N}\right.$ stretching) appeared at $1660 \mathrm{~cm}^{-1}$ after cross-linking, likely from a Schiff's base formed from reaction between GA and PEI primary amines. ${ }^{18,47,48} \mathrm{~A}$ band from primary amines ( $\mathrm{N}-\mathrm{H}$ bending) was observed at $1585 \mathrm{~cm}^{-1}$ but disappeared after cross-linking. ${ }^{49}$ The band that appeared at 1101 $\mathrm{cm}^{-1}$ after exposure to $\mathrm{CuSO}_{4}$ is likely from an overlap of stretching vibrations of $\mathrm{S}-\mathrm{O}$ (from $\mathrm{SO}^{4-}$ as the counter ion to copper) and $\mathrm{C}-\mathrm{N}$ bonds. ${ }^{50}$ The band at $1605 \mathrm{~cm}^{-1}$ indicates a copper-amine interaction. It should be mentioned that the complex signals and overlapping bands from different amine groups in PEI make it difficult to quantify the extent of crosslinking and to draw more detailed conclusions about the copper-ligand interactions.

\section{X-ray absorption spectroscopy}

In an attempt to further understand the copper binding mechanism and ligand formation, XANES analysis was conducted on copper loaded in the coatings (Fig. 7) and the results were compared to a variety of copper standards (Fig. S1, ESI $\dagger$ ). 

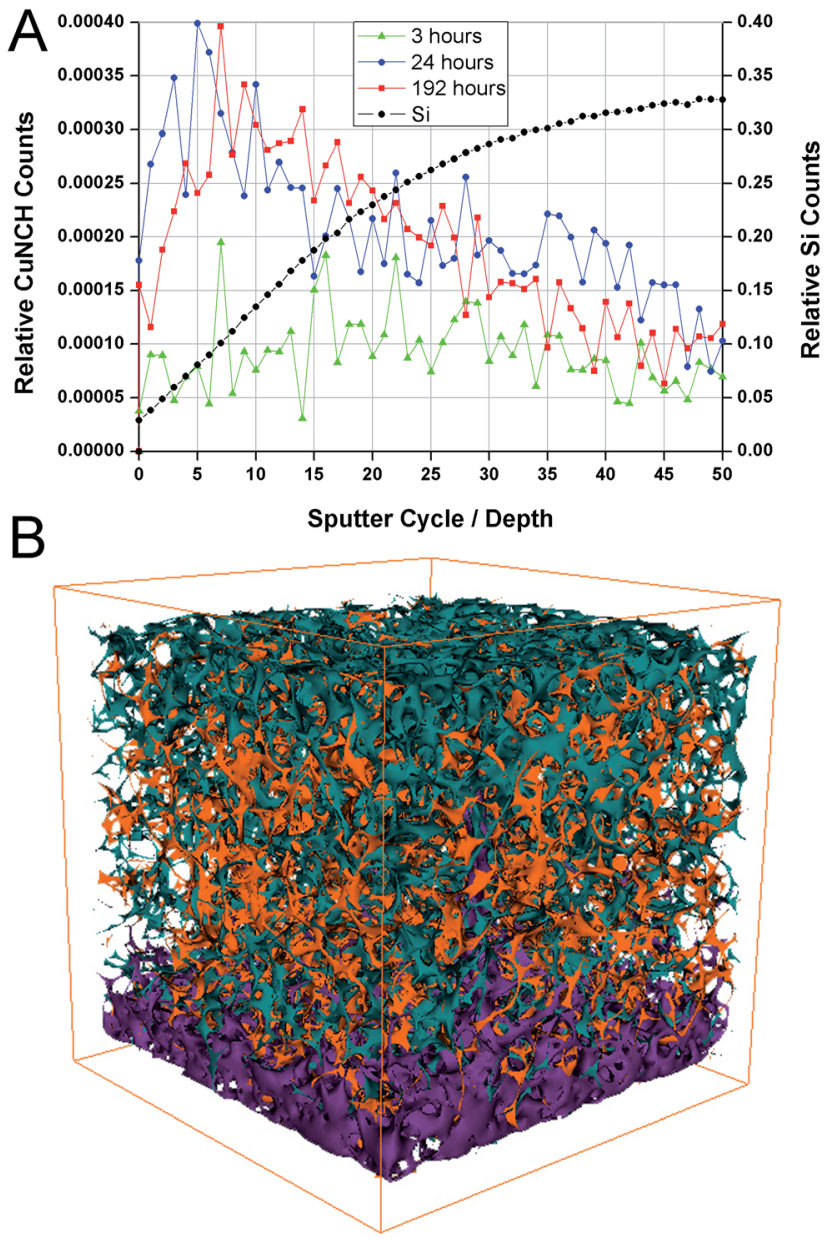

Fig. 5 ToF-SIMS depth profiles through PEI coatings on silicon wafer substrate loaded with copper through exposure to seawater. (A) Copper is shown to be incorporated into the bulk of the PEI coating rather than being adsorbed at the surface and was associated with an $\mathrm{N}$-based fragment. The amount of copper absorbed increased with time but had reached equilibrium by 24 hours. (B) A 3D reconstruction of the ToF-SIMS depth profile (conducted for the 24 hour time point) showing the coating via $\mathrm{a} \mathrm{CH}_{3}{ }^{+}$fragment (green) with embedded copper (orange) on the substrate indicated by $\mathrm{Si}^{+}$(purple). The $X$ and $Y$ axes are 100 microns while the $Z$ axis represents roughly $10 \mathrm{~nm}$, as estimated from thickness determination by ellipsometry. ${ }^{31}$

It is apparent that the copper binding environment in the GA cross-linked coatings was significantly different from that of the free PEI in solution, as evidenced by the dissimilarity between the corresponding spectra in Fig. 7. This observation may explain the extreme copper selectivity and affinity of the coatings. The altered copper-ligand environment could be due to the introduction of double bonded amines, Schiff's bases through the glutaraldehyde cross-linking. Furthermore, it was found that the aqueous environment also influenced the state of the bound copper in the coatings. As seen from comparison of the copper spectra between coatings that had been loaded with copper in Milli-Q water solution and coatings that had been loaded with copper in artificial seawater. This could possibly imply differences in counter ions and/or electrolyte charge-driven forces.

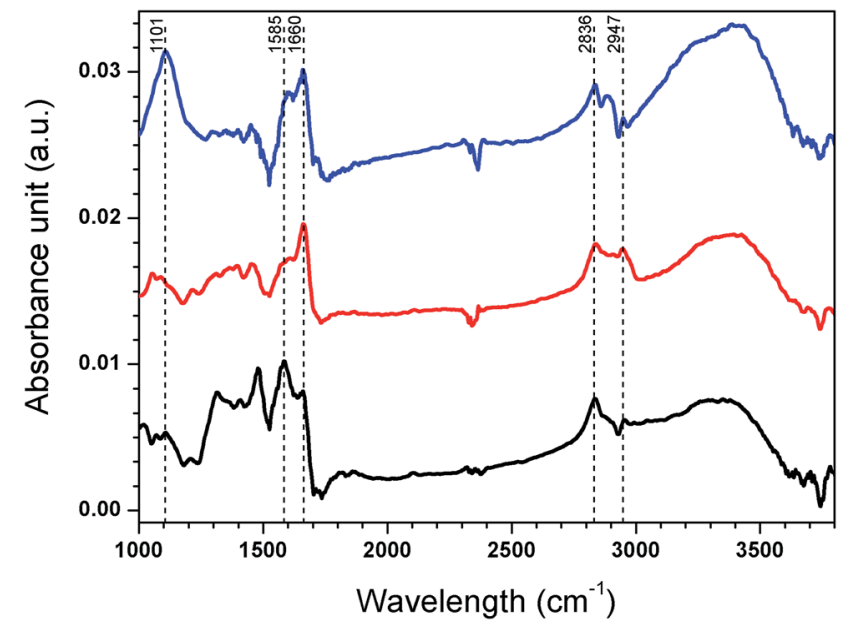

Fig. 6 ATR-FTIR spectra of spin coated PEI (black), spin coated PEI after cross-linking (red) and spin coated PEI after cross-linking and copper uptake (blue).

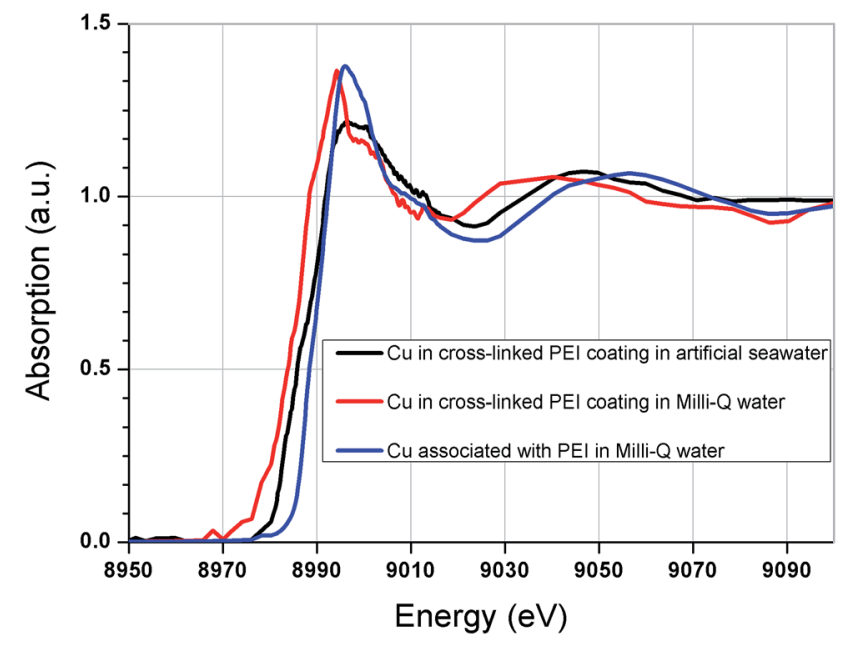

Fig. 7 Copper K-edge XANES spectra for copper; in cross-linked PEI coating in artificial seawater, in cross-linked $P E I$ coating in Milli- $Q$ water and associated with PEI in Milli-Q water.

The position of the absorption edge implies that copper was bound with an oxidation state of II, which correlates with previous findings by XPS. ${ }^{31}$ Despite comparison with a suite of 16 standard samples, linear least squares fitting was unable to provide any reasonable fit. In retrospective comparison with literature, a Schiff-base complex appears to produce a comparable spectrum to that found here. ${ }^{51,52}$ This correlates with the FTIR analysis which showed formation of Schiff's bases (imines) in the coating after cross-linking. It is also consistent with the ToF-SIMS fragmentation suggesting an N-based ligand associated with copper.

\section{Conclusions}

We expanded on our previous work on thin glutaraldehyde cross-linked PEI coatings for absorption of copper in artificial 
seawater by demonstrating the applicability to natural seawater. The coatings were shown to be nearly as effective and equally selective in seawater as in artificial seawater, despite strong indications that a conditioning organic film was formed at the coating surface. FTIR and XANES analyses indicated that GA cross-linking changed the structure from native PEI to a network with a high content of imine nitrogens (Schiff's bases). It seems likely that this structure is responsible for the extraordinary affinity and selectivity of the material towards copper.

The findings open the way for extraction and utilisation of naturally abundant copper from seawater. With regard to the proposed new concept in marine anti-biofouling, the presented material enables the first step towards this technology, i.e., the copper uptake. In future work we will move towards development of a mechanism (triggered) for releasing the copper, creating a biocidal flux across the interface, which in combination with uptake would create a continuous cycle. Furthermore, we will continue to build in-depth knowledge regarding the material properties and performance under different conditions. For example, the effect of conditioning polysaccharide films and cross-linking will be investigated.

\section{Acknowledgements}

We acknowledge that this research has been financially supported by US DARPA and ARO (Grant number W911NF1310015) and ITEK Ventures Pty Ltd, the commercialisation arm of the University of South Australia. A part of this research was undertaken on the X-ray absorption spectroscopy beamline at the Australian Synchrotron, Victoria, Australia. The authors thank Dr Peter Kappen for assistance with acquisition of the XANES data. We also acknowledge that this work was performed in part at the South Australian node of the Australian National Fabrication Facility, a company established under the National Collaborative Research Infrastructure Strategy to provide nano and micro-fabrication facilities for Australia's researchers.

\section{Notes and references}

1 K. Schiff, J. Brown, D. Diehl and D. Greenstein, Mar. Pollut. Bull., 2007, 54, 322.

2 K. Schiff, D. Diehl and A. Valkirs, Mar. Pollut. Bull., 2004, 48, 371.

3 T. W. Biggs and H. D'Anna, Mar. Pollut. Bull., 2012, 64, 627. 4 M. Srinivasan and G. Swain, Environ. Manage., 2007, 39, 423. 5 W. Chouyyok, Y. Shin, J. Davidson, W. D. Samuels, N. H. LaFemina, R. D. Rutledge, G. E. Fryxell, T. Sangvanich and W. Yantasee, Environ. Sci. Technol., 2010, 44, 6390.

6 K. Schwochau, in Inorg. Chem., Springer Berlin Heidelberg, 1984, vol. 124, p. 91.

7 U. Bardi, Sustainability, 2010, 2, 980.

8 P. E. Duru, S. Bektas, Ö. Genç, S. Patir and A. Denizli, J. Appl. Polym. Sci., 2001, 81, 197.

9 R. R. Navarro, K. Sumi, N. Fujii and M. Matsumura, Water Res., 1996, 30, 2488.
10 Y. Pang, G. Zeng, L. Tang, Y. Zhang, Y. Liu, X. Lei, Z. Li, J. Zhang and G. Xie, Desalination, 2011, 281, 278.

11 S. T. Beatty, R. J. Fischer, D. L. Hagers and E. Rosenberg, Ind. Eng. Chem. Res., 1999, 38, 4402.

12 S. T. Beatty, R. J. Fischer, E. Rosenberg and D. Pang, Sep. Sci. Technol., 1999, 34, 2723.

13 M. Chanda and G. L. Rempel, React. Funct. Polym., 1997, 35, 197.

14 R. J. Fischer, D. Pang, S. T. Beatty and E. Rosenberg, Sep. Sci. Technol., 1999, 34, 3125.

15 F. Ungaro, G. De Rosa, A. Miro and F. Quaglia, J. Pharm. Biomed. Anal., 2003, 31, 143.

16 T. Wen, F. Qu, N. B. Li and H. Q. Luo, Arabian J. Chem., 2013, DOI: 10.1016/j.arabjc.2013.06.013.

17 Z. Yuan, N. Cai, Y. Du, Y. He and E. S. Yeung, Anal. Chem., 2013, 86, 419.

18 M. Ghoul, M. Bacquet and M. Morcellet, Water Res., 2003, 37, 729.

19 S. Deng and Y.-P. Ting, Water Res., 2005, 39, 2167.

20 S. Deng and Y. P. Ting, Environ. Sci. Technol., 2005, 39, 8490.

21 M. Chanda and S. A. Pillay, Indian J. Chem. Technol., 2005, 12, 156.

22 W. K. Maketon and K. L. Ogden, IEEE Trans. Semicond. Manuf., 2008, 21, 481.

23 L. Steinmann, J. Porath, P. Hashemi and Å. Olin, Talanta, 1994, 41, 1707.

24 Y. Chen, B. Pan, H. Li, W. Zhang, L. Lv and J. Wu, Environ. Sci. Technol., 2010, 44, 3508.

25 S. Kobayashi, K. Hiroishi, M. Tokunoh and T. Saegusa, Macromolecules, 1987, 20, 1496.

26 BASF, Lupasol® types, Technical Information Sheet 08_0806130e-02, September 2010.

27 C. R. Dick and G. E. Ham, J. Macromol. Sci., Chem., 1970, 4, 1301.

28 J. Jia, A. Wu and S. Luan, Phys. Chem. Chem. Phys., 2014, 16, 16158.

29 A. Wu, J. Jia and S. Luan, Colloids Surf., A, 2011, 384, 180.

30 B. L. Rivas and K. E. Geckeler, in Polymer Synthesis Oxidation Processes, Springer, 1992, p. 171.

31 J. B. Lindén, M. Larsson, B. R. Coad, W. M. Skinner and M. Nydén, RSC Adv., 2014, 4, 25063.

32 S. J. Miklavcic, M. Nydén, J. B. Lindén and J. Schulz, RSC Adv., 2014, 4, 60349.

33 B. Ravel and M. Newville, J. Synchrotron Radiat., 2005, 12, 537.

34 B. Ravel and M. Newville, Phys. Scr., 2005, 2005, 1007.

35 W. Tong, C. Gao and H. Möhwald, Polym. Adv. Technol., 2008, $19,817$.

36 T. D. Perrine and W. R. Landis, J. Polym. Sci., Part A-1: Polym. Chem., 1967, 5, 1993.

37 H. Elderfield, H. D. Holland and K. K. Turekian, The Oceans and Marine Geochemistry, Elsevier Pergamon, 2006.

38 H. Ogawa and E. Tanoue, J. Oceanogr., 2003, 59, 129.

39 S. Abarzua and S. Jakubowski, Mar. Ecol.: Prog. Ser., 1995, 123, 301.

40 M. E. Callow and R. L. Fletcher, Int. Biodeterior. Biodegrad., 1994, 34, 333. 
41 D. M. Yebra, S. Kiil and K. Dam-Johansen, Prog. Org. Coat., 2004, 50, 75.

42 D. Briggs, J. C. Vickerman and S. Limited, ToF-SIMS: surface analysis by mass spectrometry, IM; SurfacesSpectra, Chichester, Manchester, 2001.

43 I. M. Kempson, P. Chang, K. Bremmell and C. A. Prestidge, Langmuir, 2013, 29, 15573.

44 I. M. Kempson, A. L. Martin, J. A. Denman, P. W. French, C. A. Prestidge and T. J. Barnes, Langmuir, 2010, 26, 12075.

45 I. M. Kempson, T. J. Barnes and C. A. Prestidge, J. Am. Soc. Mass Spectrom., 2010, 21, 254.

46 N. Khanam, C. Mikoryak, R. K. Draper and K. J. Balkus Jr, Acta Biomater., 2007, 3, 1050.
47 T. Wang, M. Turhan and S. Gunasekaran, Polym. Int., 2004, 53, 911.

48 W.-J. Yang, C.-S. Yang, C.-J. Huang, K.-S. Chen and S.-F. Lin, Enzyme Microb. Technol., 2012, 50, 287.

49 S. Abolmaali, A. Tamaddon and R. Dinarvand, J. Nanopart. Res., 2013, 15, 1.

50 Z. Wang and M. W. Urban, Polym. Chem., 2013, 4, 4897.

51 P. M. Dias, L. Kinouti, V. R. Constantino, A. M. Ferreira, M. B. Gonçalves, R. R. d. Nascimento, H. M. Petrilli, M. Caldas and R. C. Frem, Quim. Nova, 2010, 33, 2135.

52 A. Gaur, B. Shrivastava, K. Srivastava, J. Prasad and S. K. Singh, X-Ray Spectrom., 2012, 41, 384. 